\title{
Factors affecting survival and outcome at 3 years in extremely preterm infants
}

\author{
R W I Cooke
}

\begin{abstract}
A total of 823 infants born at 28 weeks' gestation or less were admitted to a regional referral unit between 1980 and 1989. Four hundred and sixty five $(56 \cdot 5 \%)$ survived to be discharged home. Twenty one subsequently died and two were lost to follow up. Four hundred and forty two $(53.7 \%)$ were assessed for disabilities at the age of 3 years. Eighty four (19\%) had major disabilities, of which $40(9 \%)$ were severe. A further $39(9 \%)$ had lesser disabilities. Three hundred and nineteen (63\%) survivors appeared to be functioning normally.

Logistic regression showed the likelihood of survival to be independently related to gestational age, birthweight ratio, and more recent year of birth, and inversely related to male sex and ultrasound evidence of cerebral haemorrhage or infarction. The likelihood of later disability in survivors was only independently related to cerebral ultrasound appearances.
\end{abstract}

(Arch Dis Child 1994; 71: F28-F31)

Although there are numerous reports from centres around the world about the survival and subsequent outcome of very small infants, most of these select infants for inclusion on birthweight criteria. ${ }^{1-3}$ Those using gestational age often group infants below 29 or 26 weeks' gestation together because of small numbers or have examined a short time period. ${ }^{4-6}$ Such grouping may obscure the greatest differences in outcome and changes over time.

The development and increased availability of neonatal intensive care in recent years has been associated with improved survival in infants of less than 29 weeks' gestation, and particularly in those of 24-26 weeks' gestation. This has led to renewed concern over the prevalence of disability in these high risk survivors. $^{7}$

Whether information about the correlation of subsequent disability with very low gestational age would be helpful in clinical decision making for obstetricians and paediatricians depends on whether gestation is closely related to outcome, or whether other factors such as growth retardation, male sex, or evidence of intracranial ultrasound appearances play an important part. This paper explores these issues by examining the survival and status at 3 years of all infants of less than 29 weeks' gestation admitted to a regional neonatal intensive care unit over a 10 year period.
Table 1 Descriptive and outcome variables

\begin{tabular}{|c|c|}
\hline \multicolumn{2}{|l|}{ Descriptive variables } \\
\hline Birth weight & Birth weight in grams \\
\hline Gestational age & Gestational age in completed weeks \\
\hline Sex & Male/female \\
\hline Multiple pregnancy & Yes/no \\
\hline Mode of delivery & Vagina1/caesarean section \\
\hline Place of birth & Inborn/outborn \\
\hline $\begin{array}{l}\text { Periventricular } \\
\text { haemorrhage }\end{array}$ & $\begin{array}{l}\text { Cranial ultrasound scan evidence of } \\
\text { Subependymal haemorrhage } \\
\text { Intraventricular haemorrhage } \\
\text { Parenchymal haemorrhage or } \\
\text { infarction }\end{array}$ \\
\hline \multicolumn{2}{|l|}{ Outcome variables } \\
\hline Survival & Survival to discharge from unit \\
\hline Major disability & Categories 3 and 4 (table 2) \\
\hline
\end{tabular}

Patients and methods

All infants of less than 29 weeks' gestation admitted to the Mersey regional neonatal intensive and special care unit between 1 January 1980 and 31 December 1989 were included in the study. By using the admission registers, case records, cranial ultrasound records, and microfilmed intensive care records, the year of birth and descriptive and outcome variables were obtained for each infant (table 1). Outcome data from follow up at 3 years of age were added to these data. In most cases this was carried out on a continuing annual basis by the author and consultant colleagues at the regional centre, with referral to the child development centre in selected cases. In a minority of cases follow up data were completed by using reports from local hospital paediatricians, general practitioners, or health visitors. Additional information was obtained in these cases by writing to the parents of infants not attending for follow up at the regional centre. Infants were classified into four functional disability groups using a previously published system (table 2) ${ }^{8}$ The infants in groups 3 and 4 were considered together as having a 'major disability' in this study. More minor disabilities were often only noted at a later age and their diagnosis was more subjective; they have not been considered further here. Trends in the frequency of disability by gestational age were tested where appropriate using $\chi^{2}$ for trend (table 3). The frequency of

Table 2 Functional categorisation of infants at follow up at 3 years of age

1 Normal-no clinically apparent neurodevelopmental abnormality causing functional disability

2 Mild disability - for example, myopia, language delay, mild hearing loss, hyperactivity, or motor clumsiness

3 Moderate disability - for example, spastic diplegia hemiplegia, or moderate learning disability (developmental quotient 50-69)

4 Severe disability - for example, spastic quadriplegia, blindness, deafness (loss of 70 decibels or more), uncontrolled epilepsy, or severe learning disability (developmental quotient $<50$ ). Infants with multiple disabilities

For the purposes of this study, groups 3 and 4 have been considered together as 'major disability'. 
Major disability $\mathbb{Z}$ Survived $\square$ All infants

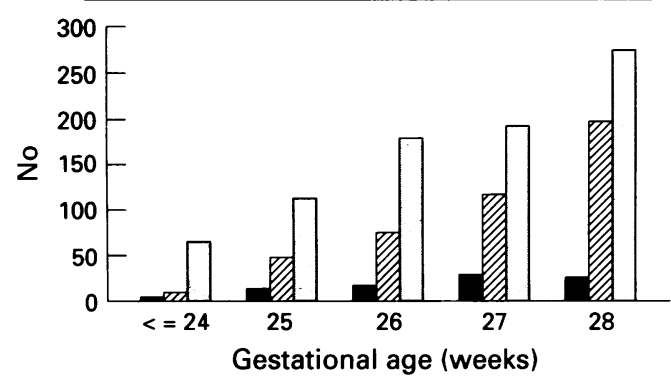

Figure 1 Survival and major disabilities at 3 years of age by gestational age.

major disability by gestation, birthweight ratio, ${ }^{9} 10$ and cranial ultrasound groups ${ }^{11}$ were compared and are shown in figs 1 and 2 and tables 4 and 5 . The birthweight ratio is the infant's birth weight divided by the mean birth weight at that gestational age.

Logistic regression analyses were performed using gestational age, birthweight ratio, male sex, place of birth, mode of delivery, multiple pregnancy, cranial ultrasound appearances, and year of birth as independent variables and survival and major disability as dependent variables. The Logit option of the Probit program in SPSS-X Release $3.1^{12}$ was used for the regression analyses, and odds ratios (ORs) and $95 \%$ confidence intervals (CIs) computed from the regression coefficients obtained. Logistic regression analysis was also used to provide annual odds ratios compared with 1980 for the likelihood of survival, or for major disability in survivors at 3 years, standardised for gestation, birth weight, male sex, place of birth, mode of delivery, and multiple pregnancy. ${ }^{2}$

\section{Results}

Eight hundred and twenty three infants of 28 weeks' gestation or less were admitted during the study period. Four hundred and sixty five $(56.5 \%)$ survived to be discharged home and $442(53 \cdot 7 \%)$ were available for follow up at 3 or more years of age. Of the 21 children who died after discharge but before 3 years, four were known to be severely disabled at the time of their deaths. Seven were recorded as being 'cot deaths', five had chronic lung disease, two had ventriculoperitoneal shunt infections, two

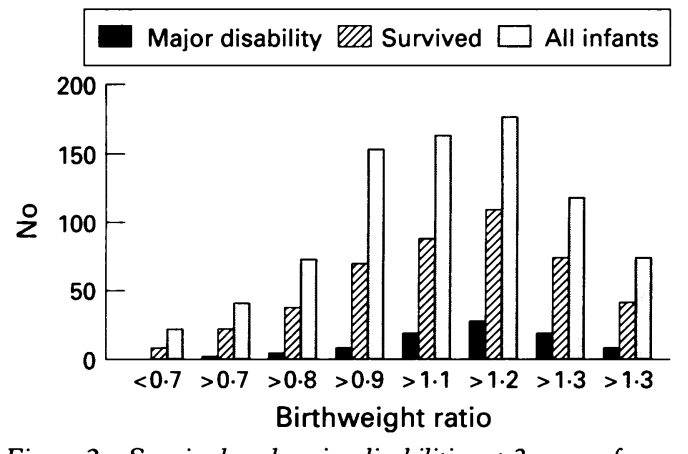

Figure 2 Survival and major disabilities at 3 years of age by birthweight ratio.

died from pneumonia, and one in a house fire. Two infants were lost to follow up. Eighty four $(19 \%)$ of the infants seen at follow up had major disabilities, of which $40(9 \%)$ were severe. A further $39(9 \%)$ infants had lesser disabilities, and $319(63 \%)$ were functioning normally (table 3). Multiple disabilities occurred in $39(9 \%)$ of the survivors followed up.

The rates of survival and of major disability were significantly related to gestational age, as were the rates of some individual disabilities (tables 3 and 4, fig 1).

The rate of survival increased with higher birthweight ratio (fig 2), as did the rate of disabilities in survivors. In survivors the rates of disabilities were related to the grade of cranial ultrasound abnormality (table 5).

Logistic regression showed that survival was independently related to gestational age (OR 1.38 , CI 1.31 to 1.50 per week), birthweight ratio (OR $1 \cdot 14$, CI 1.09 to 1.20 per 0.1 grouping of ratio), more recent year of birth (OR 1.04 , CI 1.01 to 1.07 per year), male sex (OR 0.80 , CI 0.68 to 0.94 ), and grade of periventricular haemorrhage on cranial ultrasound (OR 0.81 , CI 0.76 to 0.89 per grade), or to a parenchymal cerebral lesion on ultrasound (OR 0.54 , CI 0.44 to 0.65 ). Major disability, however, was only independently related to grade of periventricular haemorrhage (OR 1.66 , CI 1.44 to 1.91 per grade) or to the occurrence of a parenchymal cerebral lesion on ultrasound (OR $3 \cdot 52$, CI $2 \cdot 60$ to $4 \cdot 81$ ).

The standardised ORs for survival compared with 1980 showed a trend to the likelihood of increased survival towards the end of the decade and were significantly greater than

Table 3 Principal outcomes by gestational age

\begin{tabular}{|c|c|c|c|c|c|c|}
\hline & \multicolumn{6}{|c|}{ Gestational age (weeks) } \\
\hline & $\begin{array}{l}24 \\
(n=64)\end{array}$ & $\begin{array}{l}25 \\
(n=111)\end{array}$ & $\begin{array}{l}26 \\
(n=180)\end{array}$ & $\begin{array}{l}27 \\
(n=191)\end{array}$ & $\begin{array}{l}28 \\
(n=277)\end{array}$ & $p$ Value \\
\hline 3 years of age & 1 & 2 & 7 & 5 & 6 & \\
\hline Lost to follow up & 0 & 0 & 0 & 0 & 2 & \\
\hline Outcome at 3 years & & & & & & \\
\hline 'Normal' (1) & 5 & 28 & 50 & 76 & 160 & \\
\hline 'Moderate' (3) & 0 & 5 & 6 & 18 & 15 & \\
\hline 'Severe' (4) & 3 & 7 & 10 & 10 & 10 & \\
\hline $\begin{array}{l}\text { Survived to } 3 \text { years } \\
(\%, 95 \% \mathrm{CI})\end{array}$ & $\stackrel{8}{(12 \cdot 5,4 \text { to } 21)}$ & $\begin{array}{l}46 \\
(41,32 \text { to } 51)\end{array}$ & $\begin{array}{l}73 \\
(40 \cdot 5,33 \text { to } 48)\end{array}$ & $\begin{array}{l}117 \\
(61,54 \text { to } 68)\end{array}$ & $\begin{array}{l}200 \\
(72,67 \text { to } 77)\end{array}$ & $0 \cdot 000001$ \\
\hline $\begin{array}{l}\text { Major disabilities in survivors } \\
(\%, 95 \% \mathrm{CI})\end{array}$ & $(38,4$ to 71$)$ & $126,13$ to 39$)$ & $\begin{array}{l}16 \\
(22,12 \text { to } 31)\end{array}$ & $(28,16$ to 32$)$ & $\begin{array}{l}25 \\
(12 \cdot 5,8 \text { to } 17)\end{array}$ & 0.016 \\
\hline Major disabilities per liveborn infant & 3.75 to 10$)$ & 12 & 16.9 to 13$)$ & 28 & 25.0 .6 to 12$)$ & 0.085 \\
\hline
\end{tabular}

Thirteen $(3 \cdot 6 \%)$ deaths on the unit were related to lethal malformations. 
Table 4 Major disabilities at age 3 years by gestational age at birth

\begin{tabular}{|c|c|c|c|c|c|c|}
\hline & \multicolumn{6}{|c|}{ Gestational age (weeks) } \\
\hline & $\leqslant 24$ & 25 & 26 & 27 & 28 & p Value \\
\hline Total survived to 3 years & 8 & 46 & 73 & 117 & 200 & 0.000001 \\
\hline Cerebral palsy (all) & 1 & 7 & 11 & 20 & 18 & $0 \cdot 15$ \\
\hline Diplegia & 0 & 2 & 4 & 8 & 6 & \\
\hline Hemiplegia & 1 & 2 & 4 & 6 & 9 & \\
\hline Quadriplegia & 0 & 3 & 3 & 5 & 2 & \\
\hline Ataxic & 1 & 1 & & & & \\
\hline \multicolumn{7}{|l|}{ Cognitive delay } \\
\hline Severe & 0 & 4 & 5 & 3 & 4 & \\
\hline Moderate & 1 & 3 & 6 & 9 & 9 & \\
\hline Deafness & 0 & 1 & 2 & 2 & 2 & \\
\hline \multicolumn{7}{|l|}{ Visual impairment } \\
\hline Partial & 0 & 3 & 3 & 1 & 5 & \\
\hline Blind & 3 & 5 & 3 & 2 & 3 & \\
\hline Seizures & 0 & 4 & 3 & $\overline{1}$ & 3 & \\
\hline Multiple disabilities & 1 & 8 & 10 & 9 & 11 & 0.003 \\
\hline
\end{tabular}

unity in 1986 and 1989. The odds of developing a major disability as a survivor did not differ significantly from unity over the decade (fig 3).

\section{Discussion}

This study confirms the high mortality and subsequent morbidity in surviving very preterm infants and the critical effect of small differences in gestational age on these rates.

Although gestational age is a variable strongly associated with survival, it cannot be used in isolation as a basis for clinical decision making without considering other influential variables such as growth retardation (birthweight ratio), sex, or the year of birth, and the presence of major cerebral haemorrhage or infarction. The prognosis for the extremely low birthweight infant continues to improve annually. ${ }^{2}$

In this study the standardised annual odds for survival increased significantly during the decade, although the odds for major disability in survivors did not.

Interpretation of morbidity in survivors is complicated by the differential mortality of high risk infants. Most studies show a paradoxical decrease in morbidity in the lowest gestational age survivor category because of the very high risk of death in infants who might otherwise survive to be disabled. Similarly, when the effect of growth retardation is examined using the birthweight ratio, those infants showing below average growth have a higher mortality but lower rates of subsequent disability. In more mature infants, with high survival rates, low birthweight ratios are associated with higher risk of subsequent morbidities such as cerebral palsy. At very low gestational age, growth retardation increases the risk of death so that these infants do not appear among survivors.

Although gestational age was strongly associated with survival and with later

Table 5 Major disabilities by degree of periventricular haemorrhage

\begin{tabular}{lll}
\hline & $\begin{array}{l}\text { Major disabilities } \\
\text { in survivors } \\
\text { at 3 years }\end{array}$ & $\begin{array}{l}\text { Major disabilities } \\
\text { at 3 years per } \\
\text { liveborn infants }\end{array}$ \\
\hline $\begin{array}{ll}\text { No periventricular haemorrhage }(\%, 95 \% \mathrm{CI}) \\
\text { Subependymal haemorrhage }(\%, 95 \% \mathrm{CI})\end{array}$ & $\begin{array}{c}14 / 193(7 \cdot 3,4 \text { to } 11) \\
6 / 77(7 \cdot 8,2 \text { to } 14)\end{array}$ & $\begin{array}{c}14 / 288(4 \cdot 9,2 \text { to } 7) \\
6 / 92(6 \cdot 5,1 \text { to } 12)\end{array}$ \\
$\begin{array}{ll}\text { Intraventricular haemorrhage }(\%, 95 \% \mathrm{CI}) \\
\text { Parenchymal haemorrhage }(\%, 95 \% \mathrm{CI})\end{array}$ & $\begin{array}{l}26 / 115(22 \cdot 6,15 \text { to } 30) \\
26 / 57(66 \cdot 6,54 \text { to } 79)\end{array}$ & $\begin{array}{l}26 / 13(12 \cdot 2,8 \text { to } 17) \\
38 / 144(26 \cdot 4,19 \text { to } 34)\end{array}$ \\
\hline
\end{tabular}

disability if periventricular haemorrhage was not included in the logistic regression model, the inclusion of 'grade of periventricular haemorrhage' or 'parenchymal haemorrhage' removed the effect of gestation, suggesting that the poor outcome of the most preterm infants is related in the main to their increased liability to cerebral injury (table 5) and that without this even extremely preterm infant survivors may do well.

This study also highlights the problem of the biases involved in reviewing outcomes from a regional unit. The distribution of birthweight ratio on admission in this series of infants is seen to be skewed to the right (fig 2), indicating a likely selection bias in that either very growth retarded infants at this low gestation did not survive to be born alive, or died after birth but before referral. The mortality and morbidity in this study are lower than those in comparable studies based on geographically defined populations, and this probably reflects selection bias. The population in this study is estimated to consist of about $60 \%$ of those infants in Mersey region at that gestational age, but anecdotal evidence suggests that during the period studied very few infants of 26 weeks or less survived outside the regional unit. Selection bias in referral populations is thus difficult to estimate or correct for, and will vary from year to year with changing clinical expectations.

The widely varying nature of the disabilities observed in very preterm survivors makes consistency of definition of overall disability difficult and may account for some of the variation between regions or centres, though different approaches to intensity of care in poor risk infants may also play a part. Only large regional or supraregional studies will provide sufficient numbers to make confident statements about outcome in very preterm infants. Such studies need to be routine and ongoing as annual improvements continue to be made.

Although survivors at the extremes of gestation remain at high risk of developmental problems later in life, it must also be appreciated that such infants are relatively small in number and that most survivors do not have subsequent major disabilities at all. In the longer term, disabilities such as specific learning disorders and attention deficit may prove as disabling in some of these children, and only longer term follow up studies can estimate the extent of these. ${ }^{13} 14$

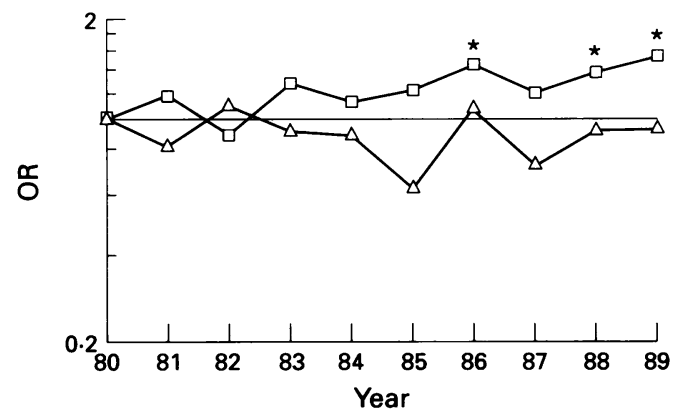

Figure 3 Standardised annual ORs for survival (squares) and for major disability at 3 years in survivors (triangles) compared with $1980(=1) .{ }^{\star} p<0.05$. 
I thank Dr A M Weindling and the many other paediatricians, family doctors, health visitors, and parents in the UK and abroad who have helped with the follow up of the children in this study.

1 Escobar GJ, Littenberg B, Petitti DB. Outcome among surviving very low birthweight infants: a meta-analysis. Arch Dis Child 1991; 66: 204-11.

2 Cooke RWI. Annual audit of three year outcome in very low birthweight infants. Arch Dis Child 1993; 63: 295-8.

3 Alberman E, Botting B. Trends in prevalence and survival of very low birthweight infants, England and Wales 1983-87. Arch Dis Child 1991; 66: 1304-8.

4 Yu VYH, Loke HL, Bajuk B, Szymonowicz W, Orgill AA, Astbury J. Prognosis for infants born at 23-28 weeks' gestation. BMF 1986; 293: 1200-3.

5 Macfarlane A, Cole S, Johnson A, Botting B. Epidemiology of birth before 28 weeks of gestation. Br Med Bull 1988; 44: 861-93.

6 Johnson A, Townshend P, Yudkin P, Bull D, Wilkinson AR. Functional abilities at age 4 years of children born before 29 weeks of gestation. BMF 1993; 306: 1715-8.
7 Davis DJ. How aggressive should delivery room cardiopulmonary resuscitation be for extremely low birthweight neonates? Pediatrics 1993; 92: 447-50.

8 Pharoah POD, Stevenson RC, Cooke RWI, Sandhu B. Costs and benefits of neonatal intensive care. Arch Dis Child 1988; 63: 715-8.

9 Brooke OG, Anderson HR, Blend JM, et al. Birthweight, stress, and behaviour: principal results from a prospective population study. BMf 1989; 298: 795-801

10 Morley R, Brooke OG, Cole TJ, Powell R, Lucas A. Birthweight ratio and outcome in preterm infants. Arch Dis Child 1990; 65: 30-5.

11 Cooke RWI. Early and late cranial ultrasound appearances and outcome in very low birthweight infants. Arch Dis Child 1987; 62: 931-7.

12 SPSS Inc. SPSS- $X$ users guide. 3rd Ed. Chicago: SPSS Inc, 1988.

13 Marlow N, Roberts BL, Cooke RWI. Motor skills in extremely low birthweight children at the age of 6 years. Arch Dis Child 1991; 64: 839-47.

14 Marlow N, Roberts BL, Cooke RWI. Outcome at 8 years for children with birth weights of $1250 \mathrm{~g}$ or less. Arch Dis Child 1993; 68: 286-90. 